\title{
Properties of Tn5-induced Carbohydrate Mutants in Rhizobium meliloti
}

\author{
By MARGARET J. DUNCAN \\ Department of Biology, Massachusetts Institute of Technology, Cambridge, \\ Massachusetts 02139, U.S.A.
}

(Received 22 April 1980)

Carbohydrate mutants were isolated from Rhizobium meliloti L5-30 using the translocatable drug-resistance element Tn5. Enzyme assays with cell-free extracts of four mutants showed that they lacked mannitol dehydrogenase, ribose kinase, xylose isomerase and fructose kinase, respectively. An L-arabinose mutant was also isolated. Uptake studies showed that the ribose, xylose and fructose mutants still utilized the sugars on which they were unable to grow, possibly indicating that $R$. meliloti possesses alternative metabolic routes which do not result in growth. All the mutants were able to nodulate alfalfa plants, but the fructose kinase mutant was unable to fix nitrogen and the L-arabinose mutant showed either late or no nitrogen-fixing ability.

\section{INTRODUCTION}

Root nodule bacteroids of the nitrogen-fixing rhizobia metabolize carbohydrates during symbiosis. The infected host plant supplies bacteroids with photosynthate containing carbon sources which they convert to energy for the maintenance of the nodule, and to ATP and electrons for the reduction of atmospheric nitrogen.

To determine which carbon compounds are used in nodules, one approach is to isolate and characterize carbohydrate mutants in free-living rhizobia (Arias et al., 1979; Duncan \& Fraenkel, 1979; Ronson \& Primrose, 1979). This paper describes the selection and characterization of such mutants in Rhizobium meliloti L5-30 which were induced by insertion of the translocatable drug-resistance element Tn5 coding for neomycin resistance. Such an element offers the advantages of giving rise to random, polar mutations by insertion of DNA which codes for readily selectable drug resistance (Kleckner et al., 1977). The Escherichia coli donor of Tn5 was that isolated by Beringer et al. (1978). They showed that Tn5 insertions in $R$. leguminosarum, $R$. trifolii and $R$. phaseoli generated auxotrophs at a frequency of about $0.3 \%$. This work demonstrates that similar screenings facilitate the isolation of sugar mutants in $R$. meliloti.

\section{METHODS}

Bacteria. Rhizobium meliloti UR1 (Arias et al., 1979) was a phosphoglucose isomerase (pgi) mutant kindly provided by G. Martinez-Drets, Instituto de Investigaciones Biologicas Clemente Estable, Montevideo, Uruguay. Its parent $R$. meliloti L5-30 (arg bio str) was obtained earlier from the same source. Escherichia coli 1830 , the Tn5 donor (Beringer et al., 1978), was from A. W. B. Johnston, John Innes Institute, Norwich.

Media. Rich medium LB and minimal medium M63 were described by Duncan \& Fraenkel (1979). In selections for neomycin resistance ( $\mathrm{Tn} 5$ expression) the antibiotic was added to these media to give a final concentration of $50 \mu \mathrm{g} \mathrm{ml}^{-1}$. Streptomycin $\left(500 \mu \mathrm{g} \mathrm{ml}^{-1}\right)$ was used to counterselect the $E$. coli donor. Carbon sources in minimal liquid and solid media were at $0.4 \%(\mathrm{w} / \mathrm{v})$, arginine was at $25 \mu \mathrm{g} \mathrm{ml}^{-1}$ and biotin was at $1 \mu \mathrm{g} \mathrm{ml}^{-1}$.

Isolation of mutant strains. Mutant isolation is outlined in Table 1. Crosses between the Tn5 donor (E. coli) and each of the $R$. meliloti recipients were performed by spreading $0.5 \mathrm{ml}$ each of exponential phase donor and recipient cultures on to $\mathrm{LB}$ plates and incubating overnight at $30^{\circ} \mathrm{C}$. The growth was then suspended in $10 \mathrm{ml}$ $0.85 \%(\mathrm{w} / \mathrm{v})$ saline, centrifuged, washed and resuspended in a final volume of $1.0 \mathrm{ml}$. When $R$. meliloti L5-30 
Table 1. Schemes for the isolation of Tn5-induced carbohydrate mutants in R. meliloti L5-30 Method 1

Cross: $E$. coli $1830 \mathrm{Str}-\mathrm{s} / \mathrm{pJB} 4 \mathrm{JI} \times R$, meliloti $\mathrm{L} 5-30 \mathrm{Str}-\mathrm{r}$

Selection: transfer of Neo-r (Tn5) on LB medium

Counterselection: against donor with streptomycin

Frequency of Neo-r: $10^{-4}$

Mutants were identified by screening for the inability to grow on specific carbon sources in minimal medium M63

\section{Method 2}

Cross: $E$. coli 1830 Str-s/pJB4JI $\times R$. meliloti UR 1 pgi Str-r

Selection: growth of the pgi mutant on L-arabinose is inhibited by many sugars, e.g. fructose (Arias et al., 1979); Neo-r was therefore selected on a minimal medium containing L-arabinose and an inhibitory sugar for simultaneous Neo-r Sugar-r

Counterselection: as in Method 1

Frequency of Neo-r Sugar-r: $10^{-6}$

In the Neo-r Sugar-r mutants the original pgi mutation was reverted on an appropriate carbon source in minimal medium. Frequency of reversion of $p g i$ : $10^{-6}$ to $10^{-8}$

was the recipient, dilutions of the mating mixture were plated on $\mathrm{LB} /$ neomycin/streptomycin plates. Neomycin-resistant, streptomycin-resistant colonies were stabbed to LB/neomycin/streptomycin plates and these purification plates were replicated to each of several carbon sources in minimal medium. Those clones unable to utilize carbon sources were examined further. When $R$. meliloti UR 1 was the recipient in the cross, the mating mixture was spread on minimal plates containing L-arabinose (as permissive carbon source) plus a carbon source which inhibited the growth of UR1, together with neomycin and streptomycin. Sugar-resistant, antibiotic-resistant colonies were streaked on the same medium as used for selection and from it colonies were tested for the retention of the pgi mutation and for sugar resistance. The pgi lesions were subsequently reverted as indicated in Results.

Determination of growth. Cultures were streaked to single colonies on M63 plates with the appropriate carbon sources and incubated at $30^{\circ} \mathrm{C}$ for $7 \mathrm{~d}$. Diameters $(\mathrm{mm})$ of well-isolated single colonies were measured. Growth in liquid culture was measured by monitoring $A_{600}$.

Preparation of cell-free extracts. A single colony of the strain to be studied was inoculated into $5 \mathrm{ml}$ LB medium and incubated overnight at $30^{\circ} \mathrm{C}$. This culture was used to seed $100 \mathrm{ml} \mathrm{LB}$ and again incubated overnight. The $100 \mathrm{ml}$ cultures were harvested in a sterile manner, washed with $100 \mathrm{ml}$ sterile $\mathrm{M} 63$ solution, resuspended in $500 \mathrm{ml} \mathrm{M} 63$ containing arginine and biotin plus carbon source at $0.4 \%$, and incubated for $48 \mathrm{~h}$. Under such conditions, the parental strain L5-30 grows utilizing the carbon source, while the mutant 'incubates' with it, and the step is used to expose both strains to putative inducing conditions for the metabolic pathway in question. Most extracts were prepared as described by Duncan \& Fraenkel (1979). Assays for ribose kinase, xylulose kinase and xylose isomerase were performed on extracts which had been centrifuged at $45000 \mathrm{rev}$. $\mathrm{min}^{-1}$ in a $50 \mathrm{Ti}$ rotor of a L5-50 Beckman ultracentrifuge for $2 \mathrm{~h}$ at $4{ }^{\circ} \mathrm{C}$. The clear, upper two-thirds of the supernatant was used for the assay.

Enzyme assays. Activities of phosphoglucose isomerase (EC 5.3.1.9), mannitol dehydrogenase (EC 1.1.1.67) and sorbitol dehydrogenase (EC 1.1.1.14) were measured as described by Arias et al. (1979) and Martinez-Drets \& Arias (1970), respectively. L-Arabinose dehydrogenase (EC 1.1.1.46) and $\alpha$-ketoglutarate semialdehyde dehydrogenase (EC 1.2.1.26) activities were assayed as described by Duncan \& Fraenkel (1979). Ribose kinase (EC 2.7.1.15) was measured as a ribose-dependent ATPase activity. The assay mixture contained (in $1 \mathrm{ml}$ ) $0.1 \mathrm{M}$-triethanolamine buffer $\mathrm{pH} 7 \cdot 6,1 \mathrm{mM}-\mathrm{ATP}, 10 \mathrm{mM}-\mathrm{MgCl}_{2}, 10 \mathrm{mM}-\mathrm{KCl}, 1 \mathrm{~mm}$-phosphoenolpyruvate, 0.2 mM-NADH, 3.5 units pyruvate kinase, 5 units lactate dehydrogenase and extract; the reaction was started by the addition of ribose ( $1 \mathrm{mM}$ ). Similarly, xylulose kinase (EC 2.7.1.17) was measured as a xylulose-dependent ATPase using xylulose (Sigma) at $1 \mathrm{~mm}$ in the reaction mixture described above. Xylose isomerase (EC 5.3.1.5) assay mixture contained (in $1 \mathrm{ml}$ ) $0.025 \mathrm{M}$-Tris/maleate buffer $\mathrm{pH} 6.9,10 \mathrm{mM}-\mathrm{MnCl}_{2}$ and extract. The assay mixture was incubated for $5 \mathrm{~min}$ at $32{ }^{\circ} \mathrm{C}$ and the reaction was started by the addition of D-xylose $(5 \mathrm{~mm})$. Samples were removed immediately and after incubation for $10 \mathrm{~min}$ at $32{ }^{\circ} \mathrm{C}$. The reaction was stopped by the addition of trichloroacetic acid to $2 \%$. The precipitated protein was removed by centrifugation, and xylulose formation in the supernatants was measured after colour development with cysteine/carbazole as described by Anderson (1966). Absorbance was measured at $540 \mathrm{~nm}$ and the amount of xylulose formed was estimated by extrapolation from a xylulose standard curve. Fructose kinase (EC 2.7.1.4) activity was assayed in a mixture containing (in $1 \mathrm{ml}$ ) $0.1 \mathrm{M}$-Tris/ $\mathrm{HCl} \mathrm{pH} \mathrm{7-0,0.4} \mathrm{mM-NADP,} 10 \mathrm{~mm}-\mathrm{ATP}, 10 \mathrm{~mm}-\mathrm{MgCl}_{2}, 10 \mathrm{~mm}$-fructose, 4 units phosphoglucose isomerase, 4 units glucose-6-phosphate dehydrogenase and extract. Protein concentration was determined by the biuret method using bovine serum albumin as standard. Enzyme activities are expressed as $\mathrm{nmol} \mathrm{min}^{-1}$ (mg protein) ${ }^{-1}$. 
Measurement of carbohydrate utilization. Ribose and xylose in culture fluids were measured by the orcinol method (Horecker, 1957). Fructose utilization was measured by the disappearance of $\left[\mathrm{U}-{ }^{14} \mathrm{C}\right]$ fructose from the incubation medium.

\section{RESULTS}

\section{Isolation of mutant strains}

Three of the mutants described in this paper (MD2, MD3 and MD5) were isolated by method 1 (see Table 1), using $R$. meliloti L5-30 as the starting strain. Two mutants, MD6 and MD7, were isolated from a pgi derivative of L5-30 (Table 1, method 2). They were selected as xylose- and sucrose-resistant derivatives, and subsequently their pgi lesions were reverted on fructose and ribose, respectively.

The overall frequency with which mutants arose in both selection methods was approximately $10^{-6}$. The successful isolation of the several different mutants indicates that Tn5 insertion is unlikely to be very specific, although the composition of the total mutagenized pool was not examined.

\section{Growth properties of the mutants}

Mutants MD2, MD3, MD5 and MD6 were specifically unable to grow on mannitol, L-arabinose, ribose and xylose, respectively, while MD7 was unable to grow on several sugars (Table 2). The mutant phenotypes were uncomplicated and on all other carbon sources tested growth was the same as that of the parent. Their lesions could be predicted readily.

\section{Enzyme lesions}

The characterization of the mutants and the appropriate enzyme activites are shown in Table 3. Mutant MD2 was defective in growth on mannitol, but not on sorbitol. Cell-free

Table 2. Growth of mutant strains on different carbon sources

$\begin{array}{lcccccc}\text { Carbon source } & \begin{array}{c}\multicolumn{7}{c}{\text { Mutants }} \\ \text { (parent) }\end{array} & \text { MD2 } & \text { MD3 } & \text { MD5 } & \text { MD6 } & \text { MD7 } \\ \text { Glucose } & + & + & + & + & + & + \\ \text { Fructose } & + & + & + & + & + & - \\ \text { Mannose } & + & + & + & + & + & + \\ \text { Mannitol } & + & - & + & + & + & - \\ \text { Sorbitol } & + & + & + & + & + & - \\ \text { Xylose } & + & + & + & + & - & + \\ \text { Ribose } & + & + & + & + & + & + \\ \text { L-Arabinose } & + & + & - & + & + & + \\ \text { Pyruvate } & + & + & + & + & + & + \\ \text { Acetate } & + & + & + & + & + & + \\ \text { Succinate } & + & + & + & + & + & +\end{array}$

+ , Growth as good as parent; -, no growth.

Table 3. Enzyme activities in cell-free extracts of mutant and parent $R$. meliloti strains

\begin{tabular}{lclrr} 
Mutant & $\begin{array}{c}\text { Carbon source used for } \\
\text { growth or induction }\end{array}$ & \multicolumn{1}{c}{ Enzyme } & $\begin{array}{c}\text { Activity* in } \\
\text { mutant }\end{array}$ & $\begin{array}{c}\text { Activity* in } \\
\text { parent }\end{array}$ \\
MD2 & Mannitol & Mannitol dehydrogenase & $<1$ & 22 \\
MD5 & Ribose & Ribose kinase & $<1$ & 106 \\
MD6 & Xylose & Xylose isomerase & $<1$ & 7 \\
& & Xylulose kinase & 43 & 22 \\
MD7 & Fructose & Fructose kinase & 14 & 66 \\
& & Mannitol dehydrogenase & 127 & 29 \\
& & Sorbitol dehydrogenase & 91 & 33
\end{tabular}

*Activities are expressed as nmol $\min ^{-1}$ (mg protein) ${ }^{-1}$. 


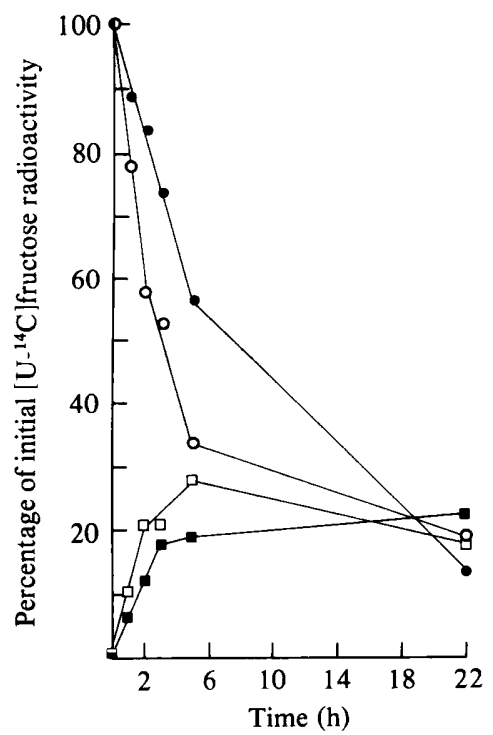

Fig. 1. Fructose utilization by strain L5-30 and mutant MD7. Bacteria were suspended $\left(A_{600} 2 \cdot 0\right)$ in medium M63 with [U-14 ${ }^{14}$ ]fructose $\left(5 \mu \mathrm{mol} \mathrm{ml}{ }^{-1} ; 165772\right.$ c.p.m. $\left.\mathrm{ml}^{-1}\right)$, arginine and biotin. Samples $(1.0 \mathrm{ml})$ were removed at the times indicated and filtered. Cell pellets were washed twice with $1.0 \mathrm{ml}$ medium M63 containing $5 \mathrm{~mm}$-fructose. Percentage of initial $\left[\mathrm{U}-{ }^{14} \mathrm{C}\right]$ fructose radioactivity in: O, culture fluids of L5-30; , culture fluids of MD7; $\square$, cells of L5-30; $\mathbf{a}$, cells of MD7.

extracts made from the mutant after induction with mannitol did not contain mannitol dehydrogenase activity. Under the same conditions mannitol dehydrogenase activity was found in extracts of the parent strain. Thus, loss of this enzyme activity accounts for the inability of mutant MD2 to grow on mannitol.

Mutant MD3 could not grow on L-arabinose, but enzyme assays showed that extracts of arabinose-treated cells contained L-arabinose dehydrogenase and $\alpha$-ketoglutarate semialdehyde dehydrogenase activities of the L-arabinose pathway (Duncan \& Fraenkel, 1979). Intermediates in the $\mathrm{L}$-arabinose pathway are unavailable commercially and the lesion in this mutant has not been characterized further. It is possible that the block is in either $\mathrm{L}$-arabinolactonase, $\mathrm{L}$-arabonate dehydratase or 2-keto-3-deoxy-L-arabonate dehydratase.

The ribose-negative mutant, MD5, grew on xylose. Its defect was therefore ribose-specific rather than a mutation in the pentose phosphate pathway. In partially purified cell extracts the mutant lacked ATP-dependent ribose kinase activity.

The xylose-negative mutant, MD6, grew on ribose. Xylose kinase activity could not be detected in cell-free extracts of the parent strain, but both parent and mutant possessed xylulose kinase activity. Xylose isomerase activity was demonstrable in the parent strain while no activity was detected in mutant MD6.

Mutant MD7 did not grow on mannitol, sorbitol "or fructose, indicating a block in fructose degradation. Cell extracts of the mutant contained approximately $20 \%$ of the fructose kinase activity of the parent L5-30. It did show mannitol and sorbitol dehydrogenase activities which were induced endogenously by the accumulation of these substances from fructose (Gardiol et al., 1980). The dehydrogenase activities found in the parent grown on fructose were much lower.

\section{Sugar utilization}

Unexpectedly, the mutants apparently metabolized the sugars whose primary degradative pathways were blocked. The utilization of $\left[\mathrm{U}-{ }^{14} \mathrm{C}\right]$ fructose by mutant $\mathrm{MD} 7$ and its parent is 
Table 4. Pentose utilization and growth of R. meliloti L5-30 and mutants MD5 and MD6

$\begin{array}{llccccc}\text { Strain } & \text { Pentose } & \begin{array}{c}\text { Time } \\ (\mathrm{h})\end{array} & \begin{array}{c}\text { Cell density } \\ \left(A_{600}\right)\end{array} & \begin{array}{c}\text { Cell } \\ \text { doublings }\end{array} & \begin{array}{c}\text { Pentose concn } \\ \text { in culture fluid } \\ \left(\mathrm{mol} \mathrm{ml}^{-1}\right)\end{array} & \begin{array}{c}\text { Pentose } \\ \text { utilized } \\ \text { over } 22 \mathrm{~h} \\ (\%)\end{array} \\ \text { L5-30 } & \text { Ribose } & 0 & 1.6 & & 41.7 & \\ & & 22 & 7.5 & 3.7 & 20.9 & 49.8 \\ \text { MD5 } & \text { Ribose } & 0 & 1.4 & & 46.7 & \\ & & 22 & 2.2 & 0.6 & 32.0 & 31.4 \\ \text { L5-30 } & \text { Xylose } & 0 & 1.5 & & 54.7 & \\ & & 22 & 3.75 & 1.5 & 23.6 & 56.8 \\ \text { MD6 } & \text { Xylose } & 0 & 1.8 & & 63.3 & \\ & & 22 & 2.9 & 0.6 & 26.4 & 58.3\end{array}$

Table 5. Frequency of revertants and their neomycin phenotype

$\begin{array}{lcccc}\text { Strain } & \text { Reversion to: } & \text { Frequency } & \begin{array}{c}\text { No. of revertants } \\ \text { examined }\end{array} & \begin{array}{c}\text { No. of Neo-s } \\ \text { revertants }\end{array} \\ \text { MD2 } & \mathrm{Mtl}^{+} & 1 \times 10^{-6} & 100 & 5 \\ \text { MD3 } & {\mathrm{L}-\mathrm{Ara}^{+}}^{+} & 1 \times 10^{-8} & 8 & 0 \\ \text { MD5 } & \mathrm{Rib}^{+} & 1 \times 10^{-8} & 9 & 0 \\ \text { MD6 } & \mathrm{Xyl}^{+} & 4 \times 10^{-6} & 100 & 2 \\ \text { MD7 } & \mathrm{Fru}^{+} & 1 \times 10^{-6} & 100 & 100\end{array}$

shown in Fig. 1. Although the mutant initially used [U-14 C]fructose at a slower rate than the parent, over $22 \mathrm{~h}$ cells of both strains had incorporated approximately the same amount of radioactivity. Also, both cultures appeared to have 'lost' an equivalent number of ${ }^{14} \mathrm{C}$ counts, i.e. radioactivity neither in the culture filtrate nor associated with the cells. In the parent strain such a loss would occur through the formation of ${ }^{14} \mathrm{CO}_{2}$ in normal fructose metabolism; it is not known what pathway is used in the mutant, but, as assayed, the lesion is fairly leaky.

The ribose and xylose mutants, MD5 and MD6, also utilized the pentoses on which they are unable to grow (Table 4). The mutant cultures utilized similar amounts of ribose or xylose to the parent, as measured by the disappearance of the sugars from culture supernatants over a period of time. Yet, while the parent culture showed at least one cell doubling, the mutants grew much less.

\section{Revertants}

Although the mutants were obtained by a protocol designed for Tn 5 insertion, it remained to be shown whether they indeed contained Tn5 inserted in the genes in question. This could not be assumed, especially since the selection using the pgi parent alone readily produces fructose kinase mutants (Gardiol et al., 1980). In fact, the fructose kinase mutant, MD7, proved to be sensitive to neomycin when retested. The other strains were neomycin-resistant and were tested for reversion to a carbohydrate-positive phenotype, the assumption being that if they were Tn 5 insertions, precise excision would be needed and the revertants would become neomycin-sensitive. Table 5 shows the reversion frequency of each mutant to the carbohydrate-positive phenotype on minimal medium. The frequencies varied from $10^{-6}$ to $10^{-8}$. A small percentage of neomycin-sensitive revertants were obtained from two of the mutants, MD2 and MD6, but the high frequency of neomycin-resistant revertants remained to be explained. Beringer et al. (1978) have reported similar results. 
Table 6. Symbiotic properties of mutants

\begin{tabular}{|c|c|c|c|}
\hline Strain & Nodulation* & Fixation & $\begin{array}{l}\text { Phenotype of bacteria } \\
\text { recovered from nodule }\end{array}$ \\
\hline MD2 & + & + & $\mathrm{Mtl}^{-}$Neo-r \\
\hline MD3 & + & $\pm \ddagger$ & L-Ara- Neo-r \\
\hline MD5 & + & + & $\mathrm{Rib}^{-}$Neo-r \\
\hline MD6 & + & + & $\mathrm{Xyl}^{-}$Neo-r \\
\hline MD7 & + & - & $\mathrm{Fru}^{-} \mathrm{Neo}-\mathrm{s}$ \\
\hline
\end{tabular}

\section{Symbiotic properties}

Table 6 shows the symbiotic properties of the mutant strains. All the mutants nodulated alfalfa plants normally by 2 weeks after inoculation. Nitrogenase, measured by acetylene reduction, could not be detected in MD7-infected plants. Four out of eleven plants inoculated with MD3 failed to show nitrogenase activity, while in the remainder fixation was delayed. In plants inoculated with MD2, MD5 or MD6 nitrogenase activity was normal.

\section{DIS C US SION}

The use of $\operatorname{Tn} 5$ for mutant selection was first demonstrated in $R$. leguminosarum by Beringer et al. (1978). This paper shows its application for obtaining sugar mutants in $R$. meliloti. At least two of the mutants (MD2 and MD6) are probably Tn 5 insertions; mutants MD3 and MD5 might also be, while in MD7 the fructose kinase lesion itself was not Tn5-induced.

The mutants described here had simple phenotypes, and their lesions could be readily demonstrated with the exception of the L-arabinose mutant. Its definitive characterization is difficult until more mutants are isolated for cross-feeding analysis and for complementation studies with cell extracts.

An interesting but puzzling finding is that mutants MD5, MD6 and MD7 utilize ribose, xylose and fructose in similar quantities to the parent strain over a long period, although they cannot grow on these substrates. It is not yet known if other metabolic products were formed. In mutant MD7, leakiness of the lesion may account for the apparent oxidation of $\left[\mathrm{U}-{ }^{14} \mathrm{C}\right.$ ]fructose to ${ }^{14} \mathrm{CO}_{2}$ but this is obviously not the case for mutants MD5 and MD6. A similar situation was reported earlier for an $a$-ketoglutarate dehydrogenase mutant which could not grow on, but still utilized, L-arabinose as well as did the parent strain (Duncan \& Fraenkel, 1979). It appears in these several cases that unless a mutant is blocked specifically in the transport of a metabolite (M. J. Duncan, unpublished results) $R$. meliloti will continue to use it. One can invoke many reasons to account for such a situation, including the following. (1) If transport of the substrate is unaffected but normal metabolism is blocked, abnormally high intracellular concentration of a sugar might induce other pathways to use it inefficiently; in this case it is difficult to explain the almost normal rate of utilization. (2) The substrate may be converted to an inert metabolite which is sequestered internally or exported to the culture fluids, this metabolite has not yet been identified. (3) There may be unknown metabolic bypasses, as proposed for the L-arabinose mutant, which, for reasons unknown, are not adequate for growth. Possibly, for advantageous reasons $R$. meliloti contains unsuspected metabolic bypasses which are not adequate for the growth of free-living cells, but suffice to maintain viability in non-growing cells.

The fructose kinase mutant nodulated alfalfa but was ineffective. The reasons for this are not obvious. If sucrose is an abundant component of the photosynthate one would expect 
that this mutant could utilize the glucose derived from it in the normal way. Ronson \& Primrose (1979) found that fructose uptake and glucose kinase mutants in $R$. trifolii were still effective. Possibly, the phosphorylation of fructose is important for effective nodulation.

The arabinose mutant, MD3, showed a delayed and variable phenotype for nitrogen fixation. In some plants fixation could not be detected even after 9 weeks and in the others it was delayed until 6 weeks. The parent L5-30 begins fixation at 3 to 4 weeks. This result, in conjunction with previous work (Duncan \& Fraenkel, 1979), suggests that L-arabinose metabolism can influence nitrogen fixation. At this stage it is not known whether the effect is direct at the level of ATP and reductant supply or indirect through the control of nitrogenase expression. All the other mutants nodulated and were effective.

This work was supported by research grant MV-381 from the American Cancer Society to Ethan Signer, whom I thank for helpful discussions. I am grateful to Dan Fraenkel for making available some of the facilities of his laboratory and to my colleagues for critical reading of the manuscript.

\section{REFERENCES}

ANDERSON, R. L. (1966). D-Lyxose isomerase. Methods in Enzymology 9, 593-596.

Arias, A., Cervenansky, C., Gardiol, A. \& Martinez-Drets, G. (1979). Phosphoglucose isomerase mutant of Rhizobium meliloti. Journal of Bacteriology 137, 409-414.

BERINGER, J. E., BeYNON, J. L., BUCHANANWollaston, A. V. \& Johnston, A. W. B. (1978). Transfer of the drug-resistance transposon Tn 5 to Rhizobium. Nature, London 276, 633-634.

Duncan, M. I. \& Fraenkel, D. G. (1979). $\alpha$ Ketoglutarate dehydrogenase mutant of Rhizobium meliloti. Journal of Bacteriology 137, 415-419.

Gardiol, A., Arias, A., Cervenansky, C., Gaggero, C. \& Martinez-Drets, G. (1980). Biochemical characterisation of a fructose kinase mutant of Rhizobium meliloti. Journal of Bacteriology 144, 12-16.

Hardy, R. W. F., Holsten, R. D., Jackson, E. K. \& BURNS, R. C. (1968). The acetylene-ethylene assay for $\mathrm{N}_{2}$ fixation: laboratory and field evaluation. Plant Physiology 43, 1185-1207.

HoRECKER, B. L. (1957). The orcinol reaction for mixtures of pentose and heptulose. Methods in Enzymology 3, 105-107.

Kleckner, N., Roth, J. \& Botstein, D. (1977). Genetic engineering in vivo using translocatable drug-resistance elements. Journal of Molecular Biology 116, 125-159.

Martinez-Drets, G. \& Arias, A. (1970). Metabolism of some polyols of Rhizobium meliloti. Journal of Bacteriology 103, 97-103.

Ronson, C. W. \& Primrose, S. B. (1979). Carbohydrate metabolism in Rhizobium trifolii: identification and symbiotic properties of mutants. Journal of General Microbiology 112, 77-88.

VincENT, J. M. (1970). A Manual for the Practical Study of Root-nodule Bacteria. Oxford: Blackwell Scientific Publications. 